\title{
As redes da Educação Integral no Distrito Federal sob o prisma da Gestão Escolar
}

\author{
Ivonete Ferreira de Sousa a \\ Ranilce Guimarães-losif ${ }^{b}$ \\ Sinara Pollom Zardo ${ }^{c}$
}

\section{Resumo}

Este artigo analisa as redes da educação integral segundo a interpretação da gestão escolar. Trata-se de um estudo qualitativo realizado em uma escola pública do Distrito Federal, baseado no método do ciclo de políticas. Utilizaramse as técnicas de análise documental e realizaram-se observações e entrevistas semiestruturadas com gestores do Projeto Educação Integral em Tempo Integral (PROEITI). Os resultados apontaram que o PROEITI avançou ao ampliar a oferta para todas as crianças matriculadas em uma jornada de 10 horas diárias, e possibilitou a contratação de professores concursados para atuar nas disciplinas complementares e nas disciplinas de informática e educação física. Os maiores desafios vivenciados pelos gestores relacionam-se à limitação de verbas para o desenvolvimento das atividades propostas pela educação integral, à carência de formação continuada dos docentes e à restrição de estrutura física das escolas.

Palavras-chave: Gestão Escolar. Educação Integral. PROEITI. Redes de Políticas.

\section{Introdução}

No contexto educacional brasileiro, as concepções e práticas de Educação Integral estão alicerçadas na ampliação da jornada escolare visam a reestruturar a escola para responder aos desafios de seu tempo histórico. A ampliação da jornada escolar, compreendida no Brasil como "escola de tempo integral", baseia-se na implantação de políticas públicas de educação que colaboram para o fortalecimento das atividades desenvolvidas no cotidiano escolar e ampliam as possibilidades de formação integral dos estudantes.

\footnotetext{
a Centro Universitário Projeção. Secretaria de Estado de Educação do Distrito Federal. Brasília, Distrito Federal, Brasil.

b University of Alberta. Department of Educational Policy Studies. Edmonton, Canadá.

c Universidade de Brasília. Departamento de Teoria e Fundamentos da Faculdade de Educação. Brasília, Distrito Federal, Brasil.
} 
Quando se fala em educação integral, identifica-se uma associação imediata à escola em tempo integral ou à ampliação da jornada escolar. Embora sejam conceitos distintos, no Brasil e no mundo, são muitas as abordagens e modelos de educação integral. No âmbito das políticas públicas de educação brasileiras, a educação integral considera o indivíduo em sua condição multidimensional, que inclui tanto a dimensão cognitiva quanto a biopsicossocial (BRASIL, 2008). A escola de tempo integral considera a questão da variável tempo - a ampliação da jornada escolar - e a variável espaço, colocada aqui como o próprio espaço da escola, como o continente dessa extensão de tempo.

A educação integral incorpora a ideia de uma oferta maior de oportunidades complementares de formação e enriquecimento curricular, como é o caso de um projeto iniciado em 2012, no Distrito Federal (DF). Esse projeto, denominado "Projeto de Educação Integral em Tempo Integral (PROEITI)", é um programa que beneficia alunos da rede pública com o aumento da jornada escolar e o desenvolvimento de atividades pedagógicas diversificadas (BLOG DE EDUCAÇÃO INTEGRAL, 2013). Essa proposta de educação integral compreende uma educação escolar ampliada em suas tarefas sociais e culturais.

Baseado no contexto da gestão da educação integral do PROEITI e nas redes de atores e instituições que a constituem, o presente artigo analisa as redes de educação integral no DF, a partir da interpretação dos gestores de uma escola vinculada ao projeto. O estudo de caso qualitativo foi realizado com base no método do ciclo de políticas (BOWE; BALL; GOLD, 1992; BALL, 1994), configura-se como um estudo empírico que investiga um fenômeno atual dentro do seu contexto de realidade e adota uma perspectiva integradora, uma vez que reúne unidades múltiplas de análise, considerando um contexto único. Ele pode ser usado para entender um fenômeno da vida real e assumir que esse entendimento provavelmente englobe importantes condições contextuais pertinentes ao seu caso (YIN, 2015).

Para o desenvolvimento deste artigo, foram selecionados quatro profissionais que participam do processo de gestão da educação integral na escola estudada, sendo um diretor escolar, um supervisor, um coordenador pedagógico e um coordenador central de educação integral. Os dados foram analisados por meio da análise de conteúdo proposta por Bardin (2010). Para o desenvolvimento das redes, foi utilizada como ferramenta o GEPHI, um software open source específico para a visualização e análise de grandes redes em tempo real.

O lócus da pesquisa foi uma escola pública da Secretaria de Estado de Educação do Distrito Federal (SEDF). A escola selecionada trabalha com os anos iniciais 
do ensino fundamental, na jornada de 10 horas/dia, e atende alunos da região com alto índice de vulnerabilidade social, necessitando, assim, de implantação de políticas públicas de combate às desigualdades. A instituição conta com a educação básica em tempo integral, oferecendo ensino fundamental do $1^{\circ}$ ao $5^{\circ}$ ano. Para a construção dos dados, foram realizadas entrevistas no ano de 2016 com os quatro gestores de educação integral que estavam envolvidos no PROEITI, além de observações e análise documental.

O artigo segue estruturado em três partes. A primeira aborda a educação integral sob a análise das redes de políticas educacionais. A segunda apresenta os gestores e a interpretação da educação integral. A terceira discute a educação integral e a demanda por uma nova gestão.

\section{A educação integral sob a análise das redes de políticas educacionais}

As políticas de educação integral surgiram em momentos diferentes e são interpretadas e traduzidas de formas diversas. Estudiosos como Anísio Teixeira $(1994 ; 1959)$ e John Dewey (1976) viram na educação um caminho estratégico para gerar as transformações necessárias à realidade brasileira e sua modernização. A educação integral idealizada pelos autores tem o pressuposto de não só formar o homem intelectualmente, mas também afetiva e socialmente, integrando tempos e espaços. Segundo Vasconcelos (2012, p. 175), "o projeto de Anísio Teixeira procurava formar os cérebros criativos e autônomos que governariam o País do futuro".

Nesse contexto, uma das experiências que o Brasil vivenciou foi a criação dos centros integrados de educação pública (Cieps), na década de 1960, que contribuiu com a ampliação da jornada escolar. A proposta se baseava na influência das experiências anisianas no Rio de Janeiro, nos anos de 1930, na Bahia, na década de 1950, e em Brasília, a partir de 1960. Além dos Cieps, outro destaque foi a implantação dos centros integrados de atenção à criança (Caics), um projeto de escola de tempo integral criado no período dos presidentes Fernando Collor de Melo e Itamar Franco. Seus conjuntos arquitetônicos foram construídos pelo país, no total de 444 unidades, exceto no Amazonas (VASCONCELOS, 2012).

Nas últimas décadas, os governos brasileiros ensaiaram várias tentativas de políticas ligadas à educação integral, dentre os quais destacam-se o Plano de Desenvolvimento da Educação (PDE), Todos Pela Educação (TPE) e o Programa Mais Educação (PME). O PDE cria estratégias para investir na educação, buscando o envolvimento dos pais, comunidade, professores, alunos e gestores. O TPE é um movimento da 
sociedade civil brasileira que surge com a promessa de contribuir para que, até 2022, o Brasil assegure a todas as crianças e jovens educação básica de qualidade. O PME propõe a articulação de políticas sociais e a implementação de ações socioeducativas oferecidas gratuitamente a crianças, adolescentes e jovens (BRASIL, 2010). A defesa da educação integral aparece também no Plano Nacional de Educação (2014-2024), que orienta as unidades federativas a ampliar políticas nessa área como mecanismo de fortalecimento da educação básica. Todavia, em 2017, é possível ver indícios de retrocessos no âmbito do financiamento das políticas educacionais, o que pode mais uma vez comprometer o projeto de educação integral no país.

No âmbito do Distrito Federal, em março de 2012, a SEDF implementou o PROEITI, cujo objetivo era oferecer uma educação integral que ajudasse estudantes em risco de vulnerabilidade a desenvolver os requisitos necessários para uma vida plena e com participação ativa na sociedade. Os alunos participantes desse projeto recebiam de 7 a 10 horas de atendimento contínuo, com aulas do ensino regular e atividades complementares, além de transporte e quatro refeições por dia - café da manhã, lanche, almoço e jantar (DISTRITO FEDERAL, 2012a).

Esse estudo considera o contexto da formulação das políticas e sua implantação e os atores locais e globais que constituem a rede das políticas de educação, a partir de uma abordagem crítica e não linear (YANG, 2015; BALL, 2014). A abordagem crítica considera a existência de grupos com diferentes valores e acessos ao poder, que competem entre si no processo de elaboração das políticas. "As políticas não surgem num vácuo; elas espelham uma série de concessões e acordos negociados entre interesses competitivos" (YANG, 2015, p. 326). De acordo com Ball (1994), políticas são, ao mesmo tempo, processos e resultados. Os significados atribuídos ao conceito de política alteram a forma como o pesquisador interpreta a política, cujos textos precisam ser lidos segundo o tempo e o local específico de sua produção e aplicação. A política educacional resulta de disputas e acordos de grupos que colaboram e/ou competem entre si no processo de representações da política.

A análise documental evidenciou a diversidade de atores (organismos) que se relacionam com o PROEITI, dos quais podemos destacar o Ministério da Educação (MEC), Ministério do Desenvolvimento Social e Combate à Fome (MDS), Ministério da Ciência e Tecnologia (MCT), Ministério do Esporte (ME), Ministério da Cultura (MC), Instituto Nacional de Estudos e Pesquisas Educacionais Anísio Teixeira (Inep), Controladoria Geral da União (CGU), Fundo Nacional de Desenvolvimento da Educação (FNDE), Programa Dinheiro Direto na Escola (PDDE), entre outros. 
A Figura 1 mostra a rede dos atores envolvidos no PROEITI, constituída por atores locais, nacionais e internacionais. Os participantes desse processo foram identificados, a partir da análise documental, por meio do estudo do contexto de influência e do contexto da produção de texto da política do PROEITI. No contexto de influência, as partes interessadas disputam a definição e propósitos sociais da educação. Envolvem grupos que influenciam o governo, mas não são eles que determinam diretamente a política (BOWE; BALL; GOLD, 1992; BALL, 1994).

No contexto de influência, foram analisadas as políticas endereçadas à educação integral e suas relações entre si. Destacam-se o cenário político - Ministérios, CGU, Inep, Secretarias, Conselho Nacional de Educação (CNE), Organização para a Cooperação e Desenvolvimento Econômico (OCDE), Organização das Nações Unidas para a Educação, a Ciência e a Cultura (Unesco), FNDE - e os parceiros ou mantenedores - Gerdau, Itaú Social, Pão de Açúcar e outros (BRASIL, 2016) -, além do Estatuto da Criança e do Adolescente (1990), do Congresso Nacional do Brasil e da Câmara Legislativa do Distrito Federal.

Já no contexto da produção de texto, foi realizada a análise e discussão das políticas nacionais e locais e dos sujeitos envolvidos. Neste estudo, foram analisados os seguintes documentos: Programa Mais Educação (Portaria Interministerial $n^{\circ}$ 17/2007 e Decreto $n^{\circ} 7.083 / 2010$ ); Portaria $n^{\circ} 1 / 2009$; Proposta Preliminar do PROEITI; Projeto Político Pedagógico da Escola estudada.

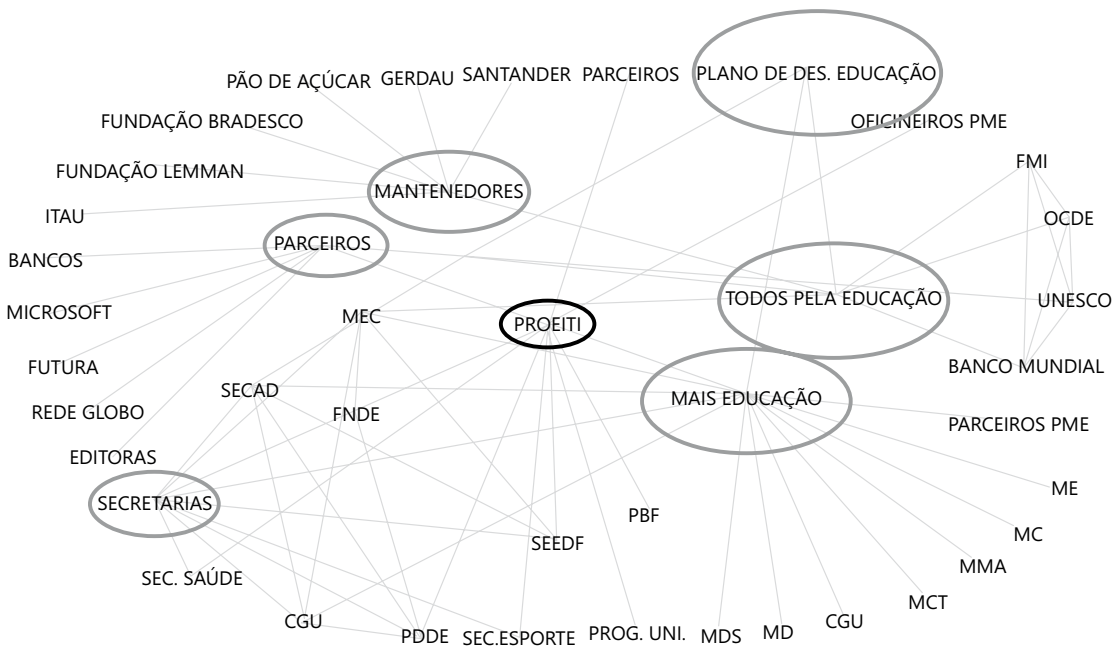

Fonte: SOUSA (2016).

Figura 1. Redes de atores envolvidos no PROEITI. 
Na rede supracitada, o PROEITI, foco do estudo em questão, representa o nó central da análise. Na concepção de que as políticas educacionais são pensadas e implantadas a partir da conectividade entre atores distintos, o texto procura destrinchar o emaranhado que cerca esse programa no contexto do DF. Os atores destacados com um círculo são os que influenciam mais diretamente as ações do PROEITI, representados na rede por meio de documentos ou de instituições ligados a gestão, financiamento ou avaliação do Projeto.

O "Mais Educação" consiste no desenvolvimento de atividades de educação integral que expandem o tempo diário de escola para o mínimo de sete horas e que também ampliam as oportunidades educativas dos estudantes. O PDE é a conjunção de esforços da União, Estados, Distrito Federal e Municípios, atuando em regime de colaboração, das famílias e da comunidade, em proveito da melhoria da qualidade da educação básica.

O TPE apela para um "pacto social", reafirmando um sentido e um significado da educação pública como parte do conjunto de estratégias políticas do "terceiro setor", que propõe a reinvenção da "sociedade civil", como uma esfera autônoma do mercado e do Estado, que deve ser orientada para a "coesão social", restaurando a solidariedade entre as classes sociais e diferentes grupos, uma nova política (GIDDENS, 1999). Essa entidade representa alguns grupos empresariais da elite brasileira que defendem um novo modelo de educação pública no país. De acordo com Martins (2008), ao assumir o compromisso com a agenda do organismo TPE, o governo abre as portas para firmar parcerias com representantes de entidades empresarias, como o Grupo Pão de Açúcar, Fundação Itaú-Social, Fundação Bradesco, Instituto Gerdau, Grupo Gerdau, Fundação Roberto Marinho, Fundação Educar-D Paschoal, Instituto Brasil Voluntário, Instituto Ayrton Senna, Banco Santander, Instituto Ethos, entre outros. Essa parceria remete a indagações sobre quais concepções e princípios vêm norteando o projeto de educação brasileira e como esse fenômeno deve ser interpretado.

As agências multilaterais, tais como o Banco Mundial (BM), a Unesco, a OCDE, são responsáveis pela definição da agenda global da educação, consultorias, avaliações e/ou proposições de "soluções" para o processo de criação de políticas nacionais. Tais influências, no entanto, são sempre recontextualizadas e reinterpretadas pelos Estados-Nação (MAINARDES, 2006).

O modelo de governança da política de educação integral brasileira é complexo, e sua compreensão demanda identificar os atores e os interesses distintos que a constituem e o modo como está sendo sua tradução nos contextos práticos 
das escolas. Atualmente, o termo governança tornou-se popular, embora seja usado na literatura acadêmica nacional e internacional de forma diferenciada. Essa popularidade deu-se devido ao papel desempenhado pelo governo e pelo surgimento de novos atores de decisão de políticas públicas. A governança refere-se às mudanças nas estruturas dos Estados, diretrizes políticas e regras de produção (SANTOS et al., 2016). Nesse contexto, destaca-se, no âmbito dos atores estatais, a atuação de alguns ministérios como MEC, MC e ME.

O ator denominado "Secretarias" envolve todas as secretarias, municipais, estaduais ou ligadas ao MEC, que apoiam o projeto de educação em tempo integral, das quais cabe destacar aquelas com mais influência na política: Secretaria de Educação Básica, Secretaria de Saúde e Secretaria de Esporte.

Já o ator "Órgãos públicos" representa os órgãos que auxiliam na gestão, financiamento ou monitoramento da educação brasileira, destacando-se Inep, CGU e FNDE. Por último, é importante destacar as relações mais sociais da política, ligada aos "Programas" que auxiliam no desenvolvimento de atividades fundantes no contexto da educação integral: "Educador Voluntário Social" e "Bolsa Família" (PBF).

A análise permite observar a marcante influência de atores nacionais e internacionais na definição das políticas de educação integral, que, por meio de acordos e parcerias, disseminam valores e concepções que sustentam as práticas educativas. As teias de relações constituídas por meio de parcerias estabelecidas entre o Estado, diferentes organismos sociais e o setor privado são denominadas por Ball (1994) de policy networks. Essas "redes têm sido configuradas com a atuação efetiva de parcerias público-privadas, pautadas nos discursos de filantropia e em um novo modelo da indústria do serviço educacional conduzidas por gestores" (SILVA; SOUZA; RICHTER, 2015, p. 2). Percebe-se que todos os atores são "peças" importantes para o desenvolvimento do PROEITI e que a análise de políticas educacionais na atualidade não pode restringir-se apenas à consideração do contexto local, regional ou mesmo nacional.

\section{Os gestores e a interpretação da educação integral do DF}

O PROEITI surgiu com a promessa de contribuir para a ampliação da jornada escolar em algumas escolas públicas do DF. A escola pesquisada, antes da implantação do projeto, funcionava com educação integral parcial e contava com nove turmas que participavam da jornada escolar de oito horas por dia. Em 2013, com a adesão ao PROEITI, 100\% dos alunos passaram a ter jornada escolar de 10 horas diárias. Mas como os gestores que atuam na escola concebem essa 
política em seu contexto prático? Este artigo discute a interpretação dos gestores da escola a partir de três eixos de análise: adesão da escola ao projeto (professores, pais e alunos); articulação intersetorial e redes de apoio (papel assistencialista do Estado); benefícios, limitações e proposições.

O primeiro eixo de análise centrou-se na "implantação do PROEITI na escola". Os resultados apontam que não houve muita aceitação dos professores no início da aplicação do projeto. Muitos mostraram-se apreensivos com a possibilidade de atuar em uma escola com uma jornada diária de 10 horas, principalmente os docentes com mais tempo de serviço na SEDF. A mudança fez com que muitos professores efetivos optassem por deixar a escola. Entretanto, com o passar do tempo, os que permaneceram aceitaram e se apropriaram do projeto. Segundo a fala dos gestores, "em 2016, não havia mais tanta rotatividade de professores, $o$ grupo era mais coeso e trabalhava em equipe para atender às expectativas do programa" (GESTOR 03).

Além dessa aversão inicial, uma das dificuldades enfrentadas pelos docentes foi a "quebra de paradigma", se comparada ao modelo regular de ensino. Com a ampliação da jornada escolar, o estudante dos anos iniciais não tem mais um único professor ministrando todas as disciplinas. O modelo possui vários professores que participam de diferentes atividades durante o dia. Os gestores relataram que os professores já estavam "acostumados" com o ensino disponibilizado pela educação formal de cinco horas diárias e tiveram certa resistência em se adaptar ao modelo atual:

“[...] a mudança foi traumática para o professor, porque na escola integral não existe o aluno do professor, existe o aluno da escola. Então, esse aluno tem na verdade dois, três, quatro professores, e antigamente esse professor era sozinho na sala de aula" (GESTOR 03).

Um dos pontos positivos identificados é que, mesmo com essa resistência inicial, os próprios docentes reconheceram que o novo modelo promoveu maior interação entre os professores, já que todos participam das atividades nos dois turnos.

Os achados demonstraram que a função da escola vai muito além do ensino. Esse convívio tem um papel relevante na vida da criança e dos que realizam o seu atendimento na escola. Segundo estudo realizado por Castro e Lopes (2011), a educação integral contribui com a criança ao fornecer-lhe uma educação direcionada para sua inserção na sociedade, coisas que provavelmente o seu meio social the negaria. Em uma escola em que a jornada é de 10 horas por dia, esse convívio tem implicações maiores, conforme enfatizado: "Então a convivência hoje em 
dia, posso dizer que é automática. É aquela máquina que funciona com as peças todas em sincronia. Todo mundo já sabe do seu papel, então a escola caminha direitinho. Todo mundo se entende, todo mundo se dá bem" (GESTOR 01).

Além do convívio das crianças, os servidores também passam por essa convivência diária. Como, na escola investigada, a maioria dos funcionários trabalha há muito tempo, percebe-se, tanto na fala dos gestores quanto nas observações feitas, que há uma familiaridade entre os servidores e no relacionamento com os pais. Conforme Moll (2008), uma escola que pensa e propõe educação integral precisa considerar saberes, histórias e trajetórias de vida de todos os sujeitos envolvidos:

Trata-se de reaproximar os tempos da vida dos tempos da escola, entendendo-os em seu continuum. Trata-se de avançar na qualificação do espaço escolar como espaço de vida, como espaço de conhecimentos e valores, como espaço no qual a vida transita em sua complexidade e inteireza [...] (p. 15).

Na perspectiva dos gestores, a interação entre família e escola também acontece de uma forma amistosa e o projeto de educação integral amplia essa potencialidade. Foi possível constatar que a maioria dos pais participam das atividades desenvolvidas pela escola, um grande ganho para a escola segundo os gestores entrevistados. A família e a escola são instituições que, juntas, podem melhorar as condições de aprendizagem, oferecendo suporte emocional e social necessários à aquisição do conhecimento.

No segundo eixo, verificou-se "a articulação intersetorial e redes de apoio", abordando o papel assumido pelo Estado na rede de governança da política. A governança surgiu de duas ondas analíticas distintas da reforma do setor público, tornando-se um termo importante em políticas e educação gerencial (SANTOS et al., 2016). Nessa perspectiva, os gestores reconhecem o caráter social desse projeto e o seu benefício para as famílias. Entretanto, um projeto não pode ser encarado a partir de um caráter assistencialista, como se a educação integral fosse importante porque "fica" com as crianças para que os pais possam trabalhar. Educar envolve compreender que o espaço em que a criança vive exige a mediação dos adultos como forma de proporcionar ambientes que estimulem a curiosidade, daí a necessidade de não pensar a educação integral na perspectiva reducionista do caráter assistencialista de uma escola ou de um projeto.

É impossível desenvolver uma educação integral sem as parcerias e as relações entre os atores que compõem o projeto em um cenário em que o Estado compartilha a gestão dos serviços públicos com outras esferas. Essa condição traz não apenas 
uma nova dinâmica na prestação de serviços em si, mas valores para o campo ideológico no que tange ao "público" (GONÇALVES, 2017). O documento "Série Mais Educação" (BRASIL, 2009) valoriza a articulação entre Educação, Assistência Social, Cultura e Esporte, dentre outras políticas públicas. Todavia, no contexto da prática, a escola precisa de mais servidores com formação específica para atuar nesses projetos e trabalhar conforme a proposta pedagógica oferecida.

Um aspecto notado nos relatos dos gestores foi que o PROEITI necessita de mais investimentos para ampliar a criação de escolas que ofertem a educação integral. Ou seja, para alcançar esse objetivo, as políticas públicas na área precisam pactuar maiores investimentos para suprir as demandas que esse tipo de escola possui (VASCONCELOS, 2012).

No eixo "benefícios, limitações e proposições" é destacado o projeto Educador Social Voluntário desenvolvido pelo Governo do Distrito Federal (GDF). Esse programa concede oportunidade de trabalho voluntário para estudantes e pessoas da comunidade com habilidades em atividades culturais, artísticas, desportivas, ambientais, culinárias e de serviços gerais. Uma de suas finalidades é dar suporte às atividades de educação integral nas unidades escolares que desenvolvem atividades de educação em tempo integral e para atuarem no atendimento educacional especializado. Nesse eixo, os gestores destacam que essa proposta é de extrema relevância para o PROEITI, pois a maioria dos selecionados possuem formação acadêmica (Pedagogia ou outras licenciaturas) ou têm experiência em dança ou atividades culturais.

Mesmo com a ajuda dos educadores voluntários, o ideal seria que todas as atividades fossem desenvolvidas por professores efetivos da SEDF. Todavia, os gestores destacaram que o projeto possibilitou a contratação de professores concursados para atuar nas disciplinas específicas de informática e educação física, um diferencial das escolas de ensino fundamental ligadas ao PROEITI.

Apesar de reconhecerem os ganhos com o projeto, os gestores falaram das principais dificuldades enfrentadas na implantação do PROEITI: limitação de verbas para o desenvolvimento das atividades propostas pela educação integral, carência de formação continuada dos docentes e restrição de estrutura física das escolas. Consideram que algumas dessas limitações poderiam ser sanadas se os repasses financeiros do PME fossem realizados regularmente, pois não houve o repasse do valor completo para as escolas (ver Quadro) nos anos de 2014 e 2015. O recurso fornecido ajudava principalmente na preparação das oficinas (compra de materiais e pequenos reparos realizados) e pagamento dos monitores/oficineiros. 
Quadro. Liberações de verbas - FNDE.

\begin{tabular}{|c|c|c|c|}
\hline \multicolumn{4}{|c|}{ PDDE - PROGRAMA DINHEIRO DIRETO NA ESCOLA } \\
\hline Data do Pagamento & Ordem Bancária & Valor & Programa \\
\hline $30 / A B R / 2014$ & $5 \times x \times 10$ & $5.960,00$ & PDDE - 1a parcela 2014 \\
\hline Total & $\mathbf{5 . 9 6 0 , 0 0}$ & \\
\hline \multicolumn{3}{|c|}{} \\
\hline PDDE - EDUCAÇÃO INTEGRAL - PROGRAMA DINHEIRO DIRETO NA EDUCAÇÃO INTEGRAL \\
\hline Data do Pagamento & Ordem Bancária & Valor & Programa \\
\hline 01/JUL/2014 & $4 \times x \times 13$ & $36.941,36$ & $\begin{array}{c}\text { MAIS EDUCAÇÃO - PDDE } \\
\text { Integral - 1a parcela 2014 }\end{array}$ \\
\hline Total & & $\mathbf{3 6 . 9 4 1 , 3 6}$ & \\
\hline
\end{tabular}

Fonte: FNDE, 2014.

Em uma consulta realizada no sítio FNDE, o último recurso recebido pela escola analisada foi feito no ano de 2014. Após essa data, a escola não recebeu mais recursos do Programa Mais Educação. Analisando os gastos financeiros de escola em tempo integral, é possível perceber que o valor recebido pelo governo é praticamente insignificante. Para desenvolver uma educação realmente integral, baseada nas concepções propostas no Projeto Político Pedagógico da escola, há necessidade de mais investimento e mais autonomia financeira. A gestão pública precisa pensar caminhos para apoiar as escolas a efetivar as condições mínimas necessárias para o desenvolvimento de programas de ampliação da jornada escolar e de educação integral.

Os gestores apontaram o espaço físico da escola como uma grande limitação da proposta, pois é inadequado para atender as demandas pedagógicas da educação integral. Constatou-se também a falta de material pedagógico para o desenvolvimento das atividades diferenciadas e a necessidade de diversificar o cardápio do almoço. No que tange às atividades de formação para a implantação do PROEITI, três entrevistados disseram que não houve curso de formação específico para a implantação do projeto, tendo havido apenas uma reunião para apresentação da proposta e sua aceitação pelos diretores escolares. Entretanto, uma das respostas indicou que houve mobilização das regionais e um curso realizado pela Escola de Aperfeiçoamento dos Profissionais da Educação (EAPE) da Secretaria de Estado de Educação do DF.

Na perspectiva dos gestores, a gestão desenvolvida na escola pública que trabalha com o PROEITI encontra-se vulnerável. As crianças ficam cansadas, os professores não têm uma preparação prévia para lidar com situações oriundas desse tipo de educação, não há participação efetiva do Conselho Escolar, os gestores tentam gerir todas as situações encontradas, mas sem apoio do Estado, faltam parceiros e principalmente verbas. Segundo Goulart (2008): 
[...] A escola, nesta concepção de educação integral, não executa sozinha todo o programa, mas se articula com outros atores sociais na ampliação de tempos, espaços e oportunidades para os alunos nela matriculados. Essa ampliação do campo da educação propõe ao administrador público um desafio para o planejamento de políticas públicas de educação. Novos sujeitos ganham legitimidade para propor políticas públicas de educação que se complementam, uma vez que as diversas linguagens são reconhecidas como parte de um mesmo processo de construção do conhecimento (p. 17).

A partir dos resultados encontrados, o estudo sugere um novo modelo de gestão para as escolas de tempo integral, pautado na integralidade de todos os participantes do processo. Esse modelo seria constituído com os pontos positivos identificados no PROEITI juntamente com outras estratégias necessárias. Com esse novo modelo de gestão, a primeira alteração que se sugere é a mudança ou adaptação do currículo utilizado - transformar o currículo fragmentado em um roteiro de aprendizagens novas e interessantes para os estudantes. As escolas em tempo integral teriam um currículo que contemplaria as atividades diferenciadas, além da utilização de mais espaços de aprendizagem. Nesse currículo contemplaria as atividades complementares que a escola desejasse ofertar e, dessa forma, os conteúdos propostos pelo Currículo em Movimento da SEDF seriam desenvolvidos de forma realmente integrada com as atividades extras escolhidas pelos estudantes (atividades físicas, pintura, dança, horta, informática).

Na educação integral, não basta aumentar o tempo de permanência do aluno na escola, de 4 para 10 horas por dia; é necessário ter mais planejamento pedagógico para aproveitar esse tempo de forma transversal. Assim, as propostas das atividades seriam objeto de reflexão, por parte do coletivo da escola, incluindo a comunidade e os próprios alunos. Outra proposição seria a alteração de ambiente escolar. Os alunos não ficariam mais 10 horas em sala de aula, pois geralmente ficam cansados de tanto copiar tarefas do quadro. Nesse novo modelo as aulas não seriam mais ministradas em sala de aula no modelo tradicional que se encontra hoje. As atividades seriam desenvolvidas em um espaço aberto, aproveitando os recursos da natureza ou locais na comunidade (seja o espaço de uma universidade, em bibliotecas, praças e outros espaços disponíveis). Para isso, é necessário que o quantitativo de alunos por turma seja reduzido para que o professor possa desenvolver essas atividades extras propostas e ter facilidade no deslocamento das crianças/adolescentes, quando necessário.

[...] a escola de tempo integral precisa estar apetrechada com instrumentações relevantes do processo de aprendizagem, tais como ambiente físico adequado, biblioteca (livros e materiais eletrônicos), 
livros didáticos de toda sorte, instrumentações audiovisuais, inclusive acesso a computador e nova mídia, sem falar em merenda (os alunos vão almoçar na escola) (DEMO, 2007, p. 9).

Outro elemento indispensável nessa nova estruturação é o tempo destinado ao descanso das crianças após o almoço, por se tratar de repouso importante para o desenvolvimento integral dos estudantes. Há necessidade de garantir o horário de descanso aliado à aprendizagem, para que haja uma rotina equilibrada nas escolas de educação integral, e o aluno não fique cansado e deixe de gostar da escola, mas sinta prazer em frequentá-la.

Sugere-se, ainda, a alteração na operacionalização do Programa Educador Voluntário Social. Levando em consideração a relevância das atividades desenvolvidas pelos jovens que compõem o programa, aponta-se como alternativa a contratação de servidores públicos para ocuparem os cargos de monitores para atuação na escola em tempo integral. Essa falta de vínculo empregatício pode levar a futuros problemas e consequências irreversíveis para as crianças, além de haver a questão de formação de dois tipos de trabalhadores na escola, um com direitos trabalhistas, e outros, não.

Outro quesito importante é a formação dos professores para atuar na educação integral. Essa formação pode ser realizada por treinamentos, cursos de extensão, congressos, debates, estudos em grupo, entre outros. Além desses treinamentos, é condição o professor querer trabalhar na educação em tempo integral, gostando de tal atividade. $\mathrm{O}$ querer trabalhar com essas crianças é primordial para o sucesso desse tipo de escola. Mas não é só esse o diferencial, havendo a necessidade da valorização do profissional para que tenha condições de dedicação exclusiva e qualificada à educação integral.

É possível, entretanto, identificar na rede apresentada (ver Figura 2), que uma proposta consistente de educação precisa ir além dos muros escolares, pois esse tipo de gestão da educação integral envolve uma variedade de componentes. Além disso, quando se aborda a gestão de uma política educacional, como o PROEITI, os componentes envolvidos são ainda maiores. Organismos nacionais, secretarias, órgãos, parceiros, comunidade e pais estão envolvidos no processo escolar por meio de ações que, muitas vezes, beneficiam a escola.

Há poucas experiências educacionais e pesquisas sobre escolas públicas em tempo integral no nosso país, e não existe nenhum modelo ideal a ser adotado. Porém, é possível identificar que uma escola de tempo integral é, hoje, o local privilegiado para desenvolver integralmente o aluno visando à sua emancipação plena como ser humano (CASTRO; LOPES, 2011). 
Esses são alguns pontos ou elementos identificados e considerados relevantes quanto à temática da educação integral ou educação em tempo integral desenvolvida no PROEITI, e que sugerem a realização de outros estudos de aprofundamento.

\section{A educação integral e a demanda por uma nova gestão}

Os dados evidenciam o reconhecimento dos gestores em relação à importância dos atores que compõem a rede de educação integral do DF, com ênfase para os mais ligados à SEDF. A rede influencia diretamente o trabalho desenvolvido em uma escola de educação integral, pois as interações estabelecidas, a partilha e a complementaridade de relações dão vida às interações. Ao se analisar a rede do PROEITI, constata-se que a interação dos atores dá origem a novas atitudes e formas de pensar, pois os membros envolvidos influenciam direta ou indiretamente a proposta de educação em tempo integral. Os gestores precisam desenvolver habilidades, conhecimentos múltiplos, apoio, redes de informação e capacidade de análise e leitura das interações existentes. Tais interações entre os atores são um ponto fundamental para que a gestão da educação integral caminhe de forma articulada.

As escolas de educação em tempo integral, de forma geral, são definidas como uma rede de espaços sociais (institucionais e não institucionais) que auxiliam na construção de comportamentos, saberes e formas de ser e estar da criança (MOLL, 2007). Ao se analisar as falas dos gestores, percebe-se que a gestão da educação integral é muito mais ampla do que a simples gestão local. O estudo considera que o modelo de educação integral ideal é aquele que trabalha com o modelo de gestão que também seja integral, ou seja, que considere a interação entre todos os atores e a educação integral. As práticas de gestão nesse contexto envolvem pais, estudantes e comunidade, de forma que todos agreguem valor à educação escolar.

Os gestores de uma escola em tempo integral precisam considerar os atores locais e externos. Não se desenvolve uma educação que contemple as diversas dimensões da formação humana sem o envolvimento de vários atores que fazem parte desse processo pedagógico (DISTRITO FEDERAL, 2012b). O modelo de educação integral articula-se com a adoção de um novo modelo de gestão que ultrapassa ações isoladas e investe na construção de relações democráticas e emancipadas com demais atores que participam da gestão local, nacional ou internacional da política. Mas a gestão local precisa, em primeiro lugar, estreitar os laços entre os atores que estão mais diretamente ligados ao contexto da escola, aqueles que recebem e implantam a política no seu cotidiano (ver Figura 2). A gestão local é o momento em que os gestores vão envolver as famílias e a comunidade a fim de incentivá-los a participar do planejamento e execução de ações que contribuam para a melhoria da escola. 
Por meio da interação dos atores é possível perceber que o processo educacional, em uma escola em tempo integral, necessita que os gestores desenvolvam uma atividade integrada com toda a comunidade escolar e para além dela, ou seja, envolvendo intensamente e intencionalmente os pais, comunidade, secretarias, parceiros, professores, entre outros. O gestor precisa ter uma visão do cenário nacional e internacional das políticas em mudança, precisa saber qual modelo de gestão compreende os elementos de governança, tais como parceria, transparência, responsabilidade e conectividade entre os atores, além disso, quais os atores interligados no projeto vigente e quais as ligações existentes entre eles.

Os problemas de uma escola em tempo integral podem ser potencializados caso os gestores mantenham um modelo de escola "fechado", um modelo não integral de ensino e de gestão. Quando os gestores têm enraizada a divisão da escola em tempos e espaços, dificilmente conseguem propor uma educação efetivamente integral, pois continuam pensando de forma fragmentada.

O aprimoramento do Programa também exige mais investimento nas escolas de educação integral, bem como mais formação para os profissionais que trabalham com os estudantes. Essa formação constitui uma necessidade à qual as universidades e a SEDF podem e devem atender, disponibilizando uma formação na perspectiva de educação integral, particularmente o desenvolvimento de uma gestão integral que se envolva intensamente com todo o processo, em nível global e local.

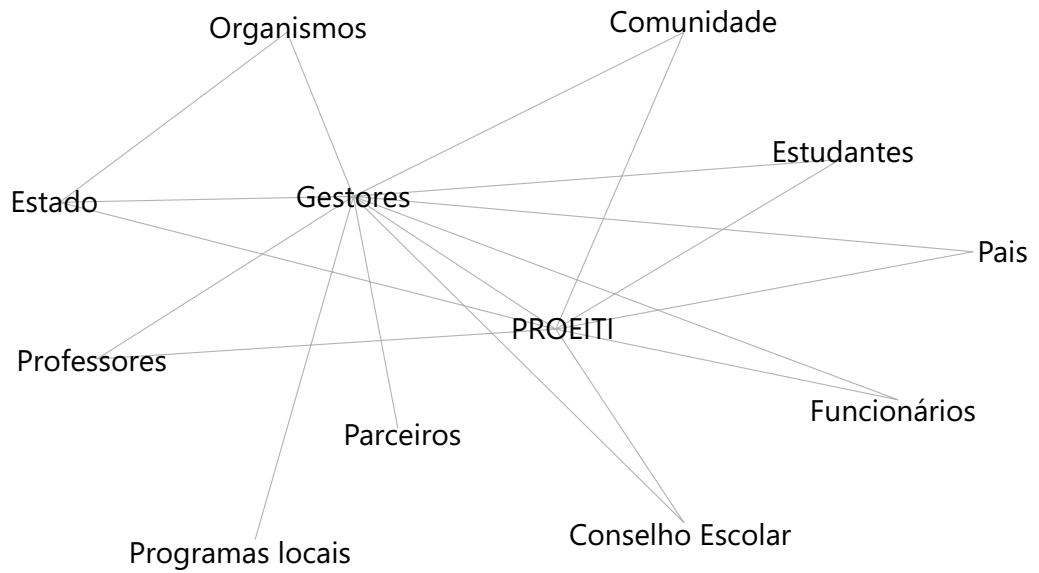

Fonte: Elaboração das autoras (2017).

Figura 2. Rede sugerida para o PROEITI. 
O modelo de gestão integral (ver Figura 3) situa-se no campo de relações conceituais e práticas da educação integral e de suas redes de governança. Todos esses atores envolvem-se globalmente em um modelo de gestão baseado na integralidade. A gestão escolar e educacional envolve pais, comunidade, estudantes e professores que interagem e fazem parte do processo de gestão que é vivenciado de várias formas, como a participação no conselho escolar - estratégia de gestão democrática da escola pública para garantir a participação da comunidade escolar na gestão das escolas. Nesse contexto, a governança educacional e os outros atores envolvidos, emergem e prometem ajudar os gestores da educação integral a encontrar respostas mais eficientes para os desafios encontrados, fortalecendo as parcerias que democratizam o acesso a uma educação de qualidade (SANTOS et al., 2016).

A fragmentação ou compartimentalização é um dos males da educação integral. Uma educação que trabalha com os pressupostos de uma educação realmente integral, não pode ser vista com uma gestão fragmentada, que trabalha somente com a microgestão escolar. "As políticas públicas setoriais são sempre pensadas de forma fragmentada, provocando sobreposição de ações entre diversos programas e projetos e provocando baixa eficácia nas ações" (GOULART, 2008, p. 17). Diante dessa realidade, constata-se que, mesmo com a existência da lei de gestão democrática do DF (DISTRITO FEDERAL, 2012b), não se percebe nas escolas a participação efetiva da comunidade. Na escola em tempo integral, a comunidade e a escola devem estar interligadas, pois, sem essa parceria, não é possível desenvolver a educação integral.

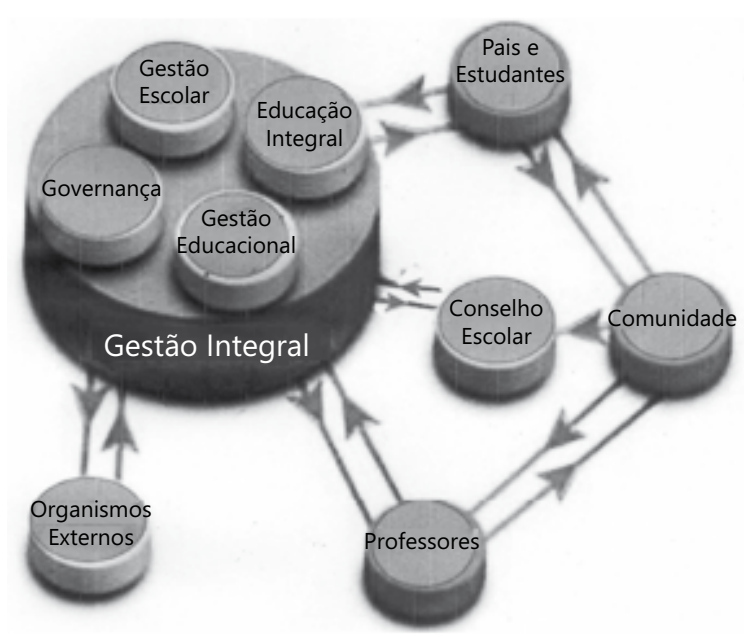

Fonte: SOUSA (2016).

Figura 3. Conceituando a Gestão Integral. 


\section{Conclusão}

No decorrer do estudo, foi possível perceber como as redes dos atores internos e externos influenciam direta e indiretamente o processo de implantação do PROEITI no contexto escolar. O estudo aponta que o projeto foi bem recebido pelos atores envolvidos na gestão da escola. São vários os avanços e os desafios no processo de gestão do PROEITI, dentre os quais destacam-se: o desenvolvimento de um processo de gestão que atenda às perspectivas locais e globais; à implementação de uma educação integral que consiga satisfazer as demandas do desenvolvimento das crianças e adolescentes; a valorização dos profissionais da educação; a melhoria do espaço físico da escola; o desenvolvimento de atividades diversificadas e a alteração do Programa Educador Voluntário Social.

Os atores da rede do contexto de influência que elaboraram a proposta PROEITI influenciam, ainda que de forma quase imperceptível, o processo pedagógico no contexto escolar. Essas redes compostas por organismos nacionais e internacionais fazem com que a escola tenha contato dia a dia com variadas iniciativas públicas e privadas, oferecendo diversos canais para que crianças, professores, gestores e comunidade acessem serviços de assistência social, saúde, esporte, cultura, e, principalmente, fazendo parte da ampla rede que compõe o sistema de ensino brasileiro.

Os resultados evidenciam a importância da interação entre os principais atores públicos e privados que compõem a rede do PROEITI. Esses atores são os mantenedores, as secretarias, os organismos externos e internos, a comunidade, os pais, os professores, entre outros, que representam elos importantes para o processo da política de educação em tempo integral. Constata-se a necessidade de mais investimento financeiro para assegurar a continuidade do projeto, contemplando a alteração do espaço físico, a formação continuada dos docentes e a garantia de professores efetivos que possam atuar nas disciplinas, as quais dinamizam e ampliam as possibilidades do currículo escolar.

Os gestores públicos, escolas e comunidades têm somado esforços para criar parcerias na construção de uma rede educativa capaz de oferecer ao aluno um ambiente que atenda às expectativas da educação integral, buscando contribuir para o desenvolvimento dos sujeitos em suas múltiplas dimensões e implementando uma das mais difíceis e desafiadoras políticas públicas. A gestão pensada na perspectiva de sua integralidade ainda constitui um grande desafio para a implantação de qualquer proposta de educação integral em contextos escolares distintos. 


\section{The networks of Integral Education in the Federal District from the perspective of school administration}

\section{Abstract}

This article analyzes the integral education networks according to the interpretation of school administration. This is a qualitative study conducted at a public school in the Federal District, based on the policy cycle method. Techniques of document analysis, observation, and semi-structured interviews were used with administrators of the Integral Education in Full Time Project (PROEITI). Results showed PROEITI advanced by expanding the offer to all children enrolled in ten-hour per day programs and made possible to hire teachers to work in complementary disciplines, as well as in computer science and physical education disciplines. Greatest challenges faced by administrators are related to the limited availability of funds for the development of activities proposed by integral education, the lack of continuous training of teachers and the restrictions imposed by the schools' physical structures.

Keywords: School Administration. Integral Education. PROEITI. Policy Networks.

\section{Las redes de la educación integral en el distrito federal bajo el prisma de la gestión escolar}

\section{Resumen}

Este artículo analiza las redes de la educación integral según la interpretación de la gestión escolar. Se trata de un estudio cualitativo realizado en una escuela pública del Distrito Federal, fundamentado en el método del ciclo de políticas. Se utilizaron las técnicas de análisis documental, y se realizaron observaciones y entrevistas semiestructuradas con gestores del Proyecto Educación Integral en Tiempo Integral (PROEITI). Los resultados apuntan que el PROEITI avanzó al ampliar la oferta para todos los niños matriculados en una jornada de 10 horas diarias y posibilitó la contratación de profesores concursados para actuar en las disciplinas complementares y en las disciplinas de informática y educación fisica. Los mayores desafios vividos por los gestores se relacionan a la limitación de presupuesto para el desarrollo de las actividades propuestas por la educación integral, a la carencia de formación continuada de los docentes y a la restricción de estructura fisica de las escuelas.

Palabras claves: Gestión Escolar. Educación Integral. PROEITI. Redes de Políticas. 


\section{Referências}

BALL, S. J. Educação global S.A: novas redes políticas e o imaginário neoliberal. Tradução Janete Bridon. Ponta Grossa: Editora UEPG, 2014.

. Educational reform: a critical and post-structural approach.

Buckingham: Open University Press, 1994.

BARDIN, L. Análise de Conteúdo. Tradução Luís Antero Reto, Augusto Pinheiro. Lisboa: Edições 70, 2010.

BLOG DE EDUCAÇÃO INTEGRAL. Projeto Piloto de Educação Integral em Tempo Integral no DF. Brasília, DF. 2013. Disponível em: $<$ http:/integraldf.blogspot.com. br/2013/01/projeto-piloto-de-educacao-integral-em.html > . Acesso em: 18 ago. 2016.

BOWE, R.; BALL, S. J; GOLD, A. Reforming education \& changing schools: case studies in policy sociology. London: Routledge, 1992.

BRASIL. Decreto No 7.083, de 27 de janeiro de 2010. Dispõe sobre o Programa Mais Educação. Diário Oficial da União, Brasília, DF, 2010. Disponível em: <http://www.planalto.gov.br/ccivil_03/_Ato2007-2010/2010/ Decreto/D7083.htm>. Acesso em: 08 dez. 2017.

.Educação Integral: texto referência para o debate nacional. Brasília, DF: Ministério da Educação, 2009. (Série Mais Educação). Disponível em: <http://portal. mec.gov.br/dmdocuments/cadfinal_educ_integral.pdf $>$. Acesso em: 08 dez. 2017.

. Fundo Nacional de Desenvolvimento da Educação. 2014. Disponível em: $<$ http://www.fnde.gov.br/pls/simad/internet_fnde.liberacoes_result_ pc?p_ano $=2014 \& p \_$programa $=Z 98$ \&p_uf $=$ DF \&p_municipio $=530010 \& p \_t p$ entidade $=\& p \_$cgc $=02432194000120>$. Acesso em: 08 dez. 2017.

. Rede de saberes mais educação: pressupostos para projetos pedagógicos de educação integral: caderno para professores e diretores de escolas. Brasília, DF: Ministério da Educação, 2008.

. Saiba Mais: Programa Mais Educação. Brasília, DF, 2016. Disponível em: $<$ http://portal.mec.gov.br/programa-mais-educacao/ apresentacao?id=16689>. Acesso em: 08 dez. 2017.

CASTRO, A.; LOPES, R. E. A escola de tempo integral: desafios e possibilidades. Ensaio: Avaliação e Políticas Públicas em Educação, v. 19, n. 71, p. 259-282, 2011. doi: http://dx.doi.org/10.1590/S0104-40362011000300003. 
DEMO, P. Escola de tempo integral. UnB, 2007. Disponível em: $<$ https:// pt.scribd.com/document/325922462/PEDRO-DEMO-ESCOLA-DE-TEMPOINTEGRAL-pdf > . Acesso em: 08 dez. 2017.

DEWEY, J. The school and society, 1899. In: . The Early works of Jonh Dewey: Early Essays and Leibniz's New Essays, 1882-1888. Carbondale: Southern Illinois University Press, 1976. p. 1-109. (Collected Works of John Dewey).

DISTRITO FEDERAL. Lei $N^{\circ}$ 4.751, de 07 de fevereiro de 2012. Dispõe sobre sistema de ensino e a gestão democrática do sistema de ensino público do Distrito Federal. Brasília, DF, 2012b: [Poder Executivo]. Disponível em: $<$ http:// www.sinprodf.org.br/wp-content/uploads/2012/06/lei-n\%C2\%BA-4751-2012da-gest\%C3\%A3o-democr\%C3\%A1tica.pdf>. Acesso em: 08 dez. 2017.

. Projeto de Educação Integral em Tempo Integral: PROEITI: versão preliminar. Brasília, DF: SEDF, 2012a.

GIDDENS, A. A terceira via: reflexões sobre o impasse político atual e o futuro da social-democracia. Rio de Janeiro: Record, 1999.

GONÇALVES, D. C. As Redes de Formação de Professores a Distância sob a Interpretação dos gestores do Sistema UAB. 2017. 161 f. Dissertação (Mestrado em Educação) - Programa de Pós-Graduação em Educação, Universidade Católica de Brasília, Brasília, 2017.

GOULART, M. A. A intersetorialidade no contexto da educação integral. Educação Integral, Brasília, DF, 2008. Disponível em: $<\mathrm{http}$ //www.ufrgs.br/projetossociais/ Biblioteca/4_TV_Escola_Educacao_Integral.pdf $>$.Acesso em: 08 dez. 2017.

MAINARDES, J. Abordagem do ciclo de políticas: uma contribuição para a análise de políticas educacionais. Artigo. Educação e Sociedade, v. 27, n. 94, p. 47-69, 2006. doi: http://dx.doi.org/10.1590/S0101-73302006000100003.

MARTINS, A. S. Todos pela educação: o projeto educacional de empresários para o Brasil do século XXI. In: REUNIÃO ANUAL DA ANPED, 31., 2008, Caxambu. Anais... Caxambu: ANPED. Não paginado. Disponível em: $<$ http://31 reuniao.anped. org.br/1 trabalho/GT09-4799--Int.pdf>. Acesso em: 8 dez. 2017.

MOLL, J. Conceitos e pressupostos: o que queremos dizer quando falamos de educação integral?. Educação Integral, Brasília, DF, ago. 2008. Disponível em: $<$ http://www.ufrgs.br/projetossociais/Biblioteca/4_TV_Escola_Educacao_ Integral.pdf >. Acesso em: 08 dez. 2017

. Desafios, avanços e limites do sistema educacional e da organização curricular no século XXI. In: SCOCUGLIA, A. Prefeitura Municipal de Gravataí. Gravataí: SMED, 2007. p. 139-148. 
SANTOS, A. V. et al. Governança: conceitos e emergência na educação brasileira. Ensaio: Avaliação e Políticas Públicas em Educação, v. 24, n. 93, p. 939-967, 2016. doi: http://dx.doi.org/10.1590/S0104-40362016000400008.

SILVA, M. V.; SOUZA, V. A.; RICHTER, L. M. Educação e classes sociais: as "redes de políticas públicas" e o ethos mercantil na esfera pública. ETD: Educação Temática Digital, v. 17, n. 3, p. 653-672, 2015. doi: https://doi.org/10.20396/etd.v17i3.8638251.

SOUSA, I. F. A gestão da educação integral: o caso de uma escola pública do Distrito Federal. 2016. 167 f. Dissertação (Mestrado em Educação) - Programa de Pós-Graduação em Educação, Universidade Católica de Brasília, Brasília, 2016.

TEIXEIRA, A. Centro Educacional Carneiro Ribeiro. Revista Brasileira de Estudos Pedagógicos, v. 31, n. 73, p. 78-84, 1959.

. Educação não é privilégio. Rio de Janeiro: Ed. UFRJ. 1994.

VASCONCELOS, R. D. As políticas públicas de educação integral: a escola unitária e a formação onilateral. 2012. xxx 278 f. Tese (Doutorado em Educação) Programa de Pós-Graduação em Educação, Universidade de Brasília, Brasília, 2012.

YANG, R. Comparações entre políticas. In: BRAY, M.; ADAMSON, B.; MASON, M. (Org.). Pesquisa em Educação Comparada: abordagens e métodos. p. 319-343. Brasília: Liber Livro, 2015.

YIN, R. K. Estudo de Caso: planejamento de métodos. 5. ed. Porto Alegre: Artmed, 2015.

\section{Informações das autoras}

Ivonete Ferreira de Sousa: Professora do Centro Universitário Projeção (UniProjeção) e da Secretaria de Estado da Educação do Distrito Federal (SEDF). Mestra em Educação pela Universidade Católica de Brasília (UCB). Contato: professoraivonete@gmail.com

Ranilce Guimarães-Iosif: Professora adjunta do Departamento de Estudos de Política Educacional, da Universidade de Alberta, Canadá. Contato: ranilceguimaraes@yahoo.com.br

Sinara Pollom Zardo: Professora do Departamento de Teoria e Fundamentos da Faculdade de Educação da Universidade de Brasília (UnB). Professora do Programa de Pós-Graduação em Direitos Humanos e Cidadania da UnB. Contato: sinarazardo@gmail.com 